\title{
Síndrome Sjögren - Larsson
}

\author{
Sjögren - Larsson syndrome
}

Leonardo Portela Rabello', Ricardo Evangelista Marrocos de Aragão², Joana Gurgel Holanda Filha ${ }^{3}$, Erlane Marques Ribeiro ${ }^{4}$, Daniele Roma Dias ${ }^{5}$, Luciana Portela Rabello ${ }^{6}$

\section{RESUMO}

Relatam-se os casos de dois irmãos consanguíneos com síndrome de Sjögren- Larsson, enfatizando a importância clínica do exame oftalmológico. BPLS, masculino, 11 anos e MBLS, feminino, 10 anos, irmãos de pais nãoconsanguíneos, apresentando ictiose congênita, diplegia espástica e retardo mental. Ao exame oftalmológico, apresentavam miopia, fotofobia, baixa acuidade visual. A fundoscopia, presença de cristais branco-amarelados em área foveal e parafoveal em ambos os olhos. Aconselhamento genético foi realizado. O manejo foi de suporte. A Síndrome de Sjögren-Larsson é uma rara doença autossômica recessiva em que há 100\% de penetrância. Síndrome de SjögrenLarsson é classicamente caracterizada por ictiose, espasticidade e deficiência mental. A doença é causada por mutações no gene aldeído desidrogenase. As alterações oculares observadas são geralmente bilaterais, cristais branco-amarelados em área retiniana, que aparecem nos dois primeiros anos de vida e que vão aumentando em número com a idade. As anormalidades oculares não têm relação com a severidade da ictiose ou com as anormalidades neurológicas. Acredita-se que as lesões oftalmológicas sejam um sinal patognomônico da síndrome. É necessário enfatizar a importância do diagnóstico precoce e possibilidades de tratamento dietético.

Descritores: Síndrome de Sjögren-Larsson; Espasticidade muscular; Ictiosis; Retardo mental; Degeneração macular; Relato de caso

\section{Abstract}

Sjogren - Larsson syndrome is a rare autosomal recessively inherited neurocutaneous disorder which occurs with $100 \%$ penetrance and is classically characterized by ichthyosis, spasticity and mental handicap. The disease is caused by mutations in the aldehyde dehydrogenase gene. The ocular manifestations are highly characteristic bilateral, glistening yellow-white retinal dots from the age of 1 to 2 years onward. The number of dots increases whit age. The extent of the macular abnormality does not correlate with the severity of the ichthyosis or with the severity of the neurological abnormalities.

We report the clinical characteristics and ocular manifestations associated with the Sjögren-Larsson syndrome in two siblings, emphasizing the clinical importance of the ophthalmological examination of the Sjögren-Larsson syndrome. BPLS, a eleven year old boy and MPLS, a ten year old girl from non-consanguinous parents, presenting congenital ichthyosis, spastic diplegia and mental retardation. Miopia, fotofobia, subnormal visual acuity and glistening yellow-white crystalline deposits that were located in the foveal and parafoveal area were found in the ophthalmologic examination.

Keywords: Sjogren-Larsson syndrome; Muscle spasticity; Ichthyosis; Mental retardation; Macular degeneration; Case report

${ }^{1}$ Residente do Serviço de Oftalmologia do Hospital Universitário Walter Cantídio, Universidade Federal do Ceará (UFC) - Fortaleza(CE), Brasil;

${ }^{2}$ Doutor, professor substituto de Oftalmologia da Faculdade de Medicina, Universidade Federal do Ceará (UFC) - Fortaleza(CE), Brasil; ${ }^{3}$ Preceptora do Serviço de Oftalmologia do Hospital Universitário Walter Cantídio, Universidade Federal do Ceará (UFC) - Fortaleza (CE), Brasil;

${ }^{4}$ Médica geneticista do Hospital Geral César Cals e Hospital Infantil Albert Sabin - Secretaria de Saúde do Estado do Ceará - Fortaleza (CE), Brasil;

${ }^{5}$ Residente do terceiro ano do serviço de Oftalmologia do Hospital Universitário Walter Cantídio, Universidade Federal do Ceará (UFC) - Fortaleza (CE), Brasil;

${ }^{6}$ Acadêmica de medicina da Faculdade de Medicina de Juazeiro do Norte - Juazeiro do Norte (CE), Brasil.

Trabalho realizado na Universidade Federal do Ceará (UFC) - Fortaleza(CE), Brasil.

Os autores declaram inexistir conflitos de interesse

Recebido para publicação em: 7/6/2010 - Aceito para publicação em 30/8/2011

Rev Bras Oftalmol. 2011; 70 (6): 416-8 


\section{INTRODUÇÃO}

$\mathbf{E}$ m 1957, Sjögren-Larsson descreveu uma síndrome caracterizada por ictiose congênita, diplegia de membros inferiores ou tetraplegia espástica e retardo mental. A doença ocorre em 1:100.000 nascimentos, sendo mais comum em caucasianos. Não há prevalência entre os sexos, pois a doença é herdada de forma autossômica recessiva $\left(\mathrm{MIM}^{*} 270200\right)^{(1,2)}$.

A Síndrome de Sjögren-Larsson (SSL) tem sido classificada como um erro inato do metabolismo caracterizado por um defeito enzimático na oxidação do álcool-graxo. O gene da SSL (aldeído desidrogenase) foi identificado no $17 \mathrm{p} 11.2$, próximo ao gene da neurofibromatose tipo I, e tem $30,5 \mathrm{~Kb}$ e 10 exons. Mais de 11 diferentes mutações foram encontradas nesse gene, causando a SSL. Os estudos bioquímicos revelaram a deficiência da enzima NAD+ oxidoredutase em portadores e afetados pela SSL. A relação entre o defeito enzimático e o quadro clínico ainda não está esclarecida $^{(1,2)}$.

Os estudos moleculares e as novas perspectivas de tratamento têm levado uma esperança para famílias de portadores de SSL. A melhoria da qualidade de vida desses pacientes depende das estratégias de tratamento delimitadas pelos médicos e pela família. Portanto, é importante o reconhecimento do quadro clínico da SSL para que o diagnóstico precoce seja seguido de um tratamento com maiores chances de sucesso ${ }^{(3)}$.

O objetivo desse artigo é relatar o caso de dois irmãos com SSL e enfatizar a importância do exame oftalmológico para diagnóstico precoce.

\section{DescriçÃo}

BPLS, 10 anos, masculino, branco e MBLS, 9 anos, feminina, branca, procedente de Caucaia - CE, filhos de pais não consanguíneos. As crianças nasceram de parto normal, a termo, apresentando ictiose desde o período neonatal e atraso de desenvolvimento neuropsicomotor. O exame físico de BPLS revelou ictiose generalizada, com predomínio em áreas de flexão, dentes espaçados, dificuldade para deambular, espasticidade em membros inferiores, retardo mental, aumento de reflexos tendinosos profundos, dificuldade na fala e déficit de coordenação motora.

O exame oftalmológico de BPLS mostrou, acuidade visual com correção (AVC) de 0.6 em ambos os olhos (AO), miopia moderada (3 d dioptrias), movi- mentos e reflexos oculares normais. Biomicroscopia, papilas conjuntivais em AO, córnea e cristalinos transparentes. Fundoscopia, presença de cristais branco-amarelados em área foveal e parafoveal (Figura 1)

$\mathrm{O}$ exame físico de MBLS mostrou pele com aspecto de ictiose, porém mais leve do que a do irmão. $\mathrm{O}$ retardo mental leve. O exame oftalmológico, AVC de 0.6 em AO, miopia moderada (3D), presença de cristais branco-amarelados em área parafoveal à fundoscopia (Figura 2). A evolução de ambos tem sido com piora gradual e lenta do quadro neurológico. O aconselhamento genético foi realizado.

\section{Discussão}

A SSL é uma doença genética rara, de herança autossômica recessiva, em que há penetrância completa, expressividade variável e que se caracteriza por ictiose congênita, diplegia espástica de membros inferiores e retardo mental ${ }^{(4)}$.

As alterações neurológicas das crianças com SSL são graves. Devido à retração fibrotendínea e à hipotrofia muscular, os afetados podem ser impedidos de deambular, o que ocorre em $75 \%$ dos casos. A espasticidade nas fases avançadas da doença pode atingir os membros superiores e a região perioral, dificultando a fala e a alimentação. O retardo mental é acentuado. Em alguns casos há crises convulsivas ${ }^{(5)}$. A ictiose é generalizada, presente desde o nascimento e mais visível no primeiro ano de vida ${ }^{(3,6)}$, sendo mais grave em áreas de flexão e nas regiões palmo-plantares, como nos casos que descrevemos.

As manifestações oculares incluem pontos cintilantes, branco-amarelados, em área macular da retina, de causa não conhecida. A presença destes cristais foveais e parafoveais é de importância cardeal e, provavelmente, um sinal patognomônico desta síndrome. Pode haver também miopia moderada, blefarite, conjuntivite e fotofobia ${ }^{(3,7,8)}$.

Outras anomalias são baixa estatura, hipertelorismo, dentes afastados, hipoplasia do esmalte dentário e cifoescoliose. ${ }^{(3)}$ Apenas o caso 1 mostrou ao exame clínico a presença de dentes espaçados. As outras anomalias não foram detectadas nos casos que descrevemos.

O diagnóstico diferencial da SSL deve ser feito com paralisia cerebral, pelo comprometimento neurológico, síndrome de Rud, por convulsão, retardo mental, ictiose congênita, sem espasticidade e síndrome DeSantis-Cacchione, pelo comprometimento neurológi- 


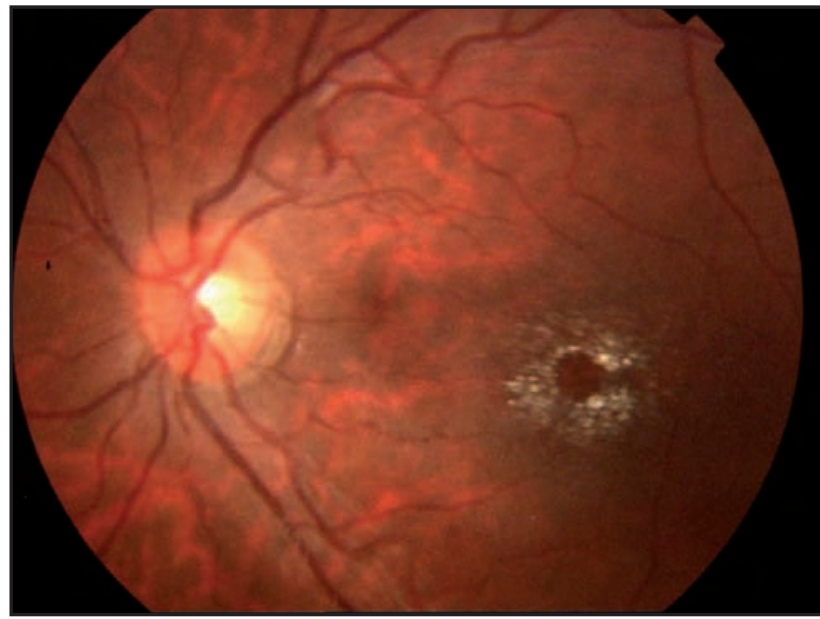

Figura 1: Retinografia com presença de cristais branco-amarelados na área foveal e parafoveal do olho esquerdo do paciente BPLS na idade de 10 anos

co e dermatológico, além da ictiose vulgar, em que o comprometimento neurológico está ausente e síndrome de Refsum, em que há ictiose, ataxia e polineuropatia ${ }^{(4,5,7)}$.

O prognóstico depende das anomalias neurológicas. A sobrevida é em torno de 30 anos de idade ${ }^{(3,5)}$.

O diagnóstico pré-natal e de heterozigotos é possível a partir de estudos moleculares com a identificação da mutação específica da família em questão ou da deficiência enzimática, onde a atividade da NAD+oxidoredutase é diminuída. ${ }^{(1,9)} \mathrm{O}$ exame oftalmológico é de suma importância, pois as alterações oculares ocorrem logo nos primeiros anos de vida, sendo necessário tratamento dos erros refrativos, ambliopia e, muitas vezes, reabilitação visual.

O tratamento é sintomático. Têm sido propostos tratamentos novos para SSJ, incluindo a restrição de gordura e suplementação com triglicerídeos de cadeia média. O uso de etretinato, na dose de $0,25 \mathrm{mg} / \mathrm{Kg}$, pode reduzir o prurido dos pacientes. É indicada escolarização em classe especial ou inclusiva ${ }^{(2)}$. No caso de SSL, o aconselhamento genético é imperativo ${ }^{(9)}$.

\section{REFERÊNCIAS}

1. Online Medelian Inheritance in Man - OMIN. [Internet]. [cited 2004 Ago 30]. Available from: http://www.ncbi.nlm.nih.gov/ Omim/mimstats.html

2. Taube B, Billeaud CL, Fontan D, Entressangles B, Taieb A, Tanaka AMU. Sjögren-Larsson syndrome: an appraised of the literature and presentation of two cases. Rev Bras Clin Ter. 1999;25(2):88-92.

3. Coleman M. Sjögren-Larsson syndrome. In: Buyse ML. Birth defects encyclopedia. Cambridge, MA: Blackwell Scientific Publications; 1990. p. 1544-5.

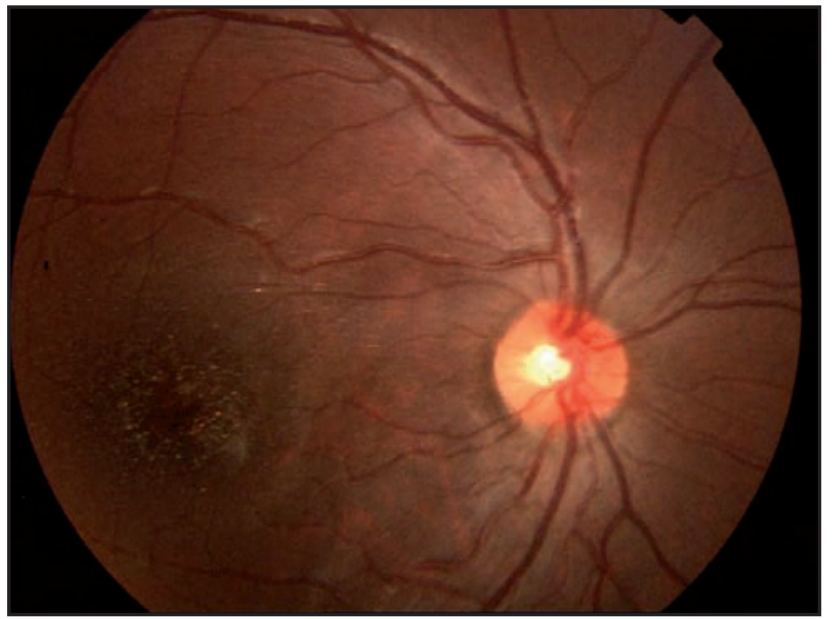

Figura 2: Retinografia com presença de cristais branco-amarelados em região foveal e parafoveal do olho direito do paciente MBSL na idade de 9 anos

4. Oliveira BCG, Roux CC, Fonseca GA, Carvalho JLT. Síndrome de Sjögren Larsson: relato de três casos. Med Reabil. 1987;(17):1-3

5. Sanvito WL. Sjögren Larsson. In: Sanvito WL. Síndromes neurológicas. 2a ed. São Paulo: Atheneu; 1997. p. 457-8

6. Behrman RE. Sjögren Larsson syndrome. In: Behrman RE, Kliegman RM, Jenson HB, editors. Nelson textbook of pediatrics. 17th ed. Philadelphia: W.B. Saunders; 2004. p. 2203.

7. Marques Dias MJ, Lefevre AB, Gonzalez CH, Saldanha PH. Síndrome de Sjogren-Larsson: estudo clínico e laboratorial de dois casos. Arq Neuropsiquiatr. 1983;41(4):367-72.

8. Willemsen MA, Cruysberg JR, Rotteveel JJ, Aandekerk AL, Van Domburg PH, Deutman AF. Juvenile macular dystrophy associated with deficient activity of fatty aldehyde dehydrogenase in Sjögren-Larsson syndrome. Am J Ophthalmol. 2000;130(6):782-9.

9. Ribeiro EM. Aconselhamento genético. RBM Rev Bras Med. 2001;58(7):490-6.

Endereço para correspondência:

Ricardo Evangelista Marrocos de Aragão

Rua Osvaldo Cruz, 2335 Bairro Dionísio Torres

CEP 60125-151 - Fortaleza(CE), Brasil

E-mail: ricardomarrocos@yahoo.com 